\title{
Las cosas llegan, pero hay que echarles mucha paciencia
}

\section{Good things come to those who are patient}

\section{Neila García SALGado}

Traductora autónoma, ACE Traductores

neila.garsal@gmail.com

\section{INTRODUCCIÓN}

Neila García Salgado es una antigua alumna de la Facultad de Traducción y Documentación de la Universidad de Salamanca. Fue galardonada con el Premio Nacional a la mejor traducción de 2018 por Encontraste un alma, poesía completa, de Edith Södergran, una traducción del sueco al castellano. Sus lenguas de trabajo son el inglés, el alemán, el sueco, y traduce hacia el español y el gallego. Además, es socia de ACE traductores y una gran defensora de la labor de los traductores.

Palabras clave: traducción; traducción literaria.

\section{ENTREVISTA}

Fecha: 11/15/2018

Don de Lenguas: Neila, muy buenas tardes. Estamos encantados de tenerte con nosotros y la primera pregunta, que es casi obligada, es qué supone para ti haber ganado este galardón. 
Neila García Salgado: Buenas tardes y encantada yo también de acompañaros. En primer lugar, supone un gran reconocimiento por todo el trabajo dedicado. También un gran reconocimiento hacia la autora, porque, pese a haberse traducido antes al español, hasta ahora no había tenido mucha repercusión. Considero, además, que no solo es un galardón para mí, sino también para la autora, e incluso para el editor y para la editorial que apostaron por esta autora y por mí como traductora.

DDL: Y, como hemos dicho, es un premio por una traducción del sueco al castellano.

NGS: Sí.

DDL: Por lo general, en nuestra Facultad el sueco no suele ser una lengua de trabajo muy frecuente entre los alumnos. ¿Cómo entraste tú en contacto con este idioma?

NGS: Cuando yo era estudiante de Traducción, una de las universidades que tenía un convenio Erasmus con nuestra Facultad era la Universidad de Gotemburgo. Yo siempre había sentido interés por las lenguas escandinavas. Entonces, cuando pude elegir adónde marcharme a estudiar, decidí que pasaría un semestre en un destino de habla inglesa y otro semestre en un destino de habla alemana. La Universidad de Gotemburgo impartía clases en inglés, por lo que me pareció una buena oportunidad de tener toda esa carga académica en inglés y, al mismo tiempo, poder aprender otro idioma más.

DDL: También nos gustaría preguntarte, como experta que suponemos que eres en este idioma, si hay alguna peculiaridad o algo curioso que hayas descubierto a la hora de traducir del sueco al español. Alguna particularidad del idioma o algo así.

NGS: Yo creo que todos los idiomas tienen particularidades y diría que las comparten en gran medida con las demás lenguas de su misma familia. En el caso concreto de la poesía de Södergran, y de casi toda la poesía escrita en sueco - al menos de la que yo conozco-, señalaría la manera de marcar el ritmo, muy distinta con respecto al español.

DDL: ¿También haces traducción inversa?

NGS: Al sueco, no.

DDL: Bueno, era una pregunta que queremos hacer para para cerciorarnos porque suponemos que cuando no es la lengua materna es más complejo traducir hacia ella. Quizás más asequible para una persona cuya lengua materna es el español y que está aprendiendo sueco, traducir del sueco.

Neila Garcia SALGADO Las cosas llegan, pero hay que echarles mucha paciencia 
NGS: Yo no me atrevo, por lo general, a hacer traducción inversa. Sí traduzco en ambas direcciones con el español y el gallego, porque las dos son lenguas maternas. Hacia el sueco no me atrevería a traducir. Sí me atreví a alguna vez a traducir e interpretar hacia el inglés, porque en determinados contextos sí me siento cómoda. Pero, por lo general, no hago traducciones inversas.

DDL: De acuerdo, sí. Totalmente normal, claro. Como la están enseñando en la Facultad, la inversa es realmente complicado para gente que no es su lengua materna. $Y$ nos gustaría preguntarte sobre la obra en cuestión, que es una obra de Edith Södergran. ¿Podrías hablarnos un poco sobre sobre la autora, su poesía? ¿Cómo encontraste esta obra? ¿Cuál es tu opinión?

NGS: La autora es una poeta de principios del siglo XX. Y es un caso curioso porque nació en un territorio fronterizo de la actual Rusia, pero escribía en sueco. Creció dentro de una minoría suecoparlante, pero su lengua académica era el alemán. Leía mucho en alemán, en ruso, en francés... Por todo ello, la propia elección de en qué lengua escribir le fue complicada. Sus primeros poemas, de hecho, están en alemán. No figuran, dicho sea de paso, en la obra de Encontraste un alma porque se suelen considerar ejercicios poéticos más que poesía en sí. Diría que eso es lo más reseñable sobre la autora. Y entré en contacto con ella a través de un amigo sueco al que conocí durante mi estancia en Alemania, porque yo había estudiado ya sueco en Suecia, luego fui a Alemania a estudiar, y ahí pude continuar con mis estudios del sueco. Se dio la casualidad de que tenía un amigo sueco, que fue quien me introdujo en la literatura más clásica, en los nombres más conocidos de la literatura clásica en sueco.

DDL: También, visto el éxito de esta traducción, nos preguntamos si vamos a tener la ocasión de disfrutar de algún otro trabajo tuyo, alguna otra traducción de autores suecos hacia el español.

NGS: Sí, no sé si lo puedo decir. Ahora mismo estoy traduciendo una novela también de principios del siglo XX de un autor cuyo nombre, por si acaso, no revelaré, pero sí puedo decir que ese autor está traducido al español, si bien hasta ahora no se tradujo directamente desde el sueco. Ahora mismo estoy traduciendo la que quizá sea su obra más conocida, directamente del sueco. Después de este proyecto, tengo también otro, pero es totalmente diferente. Es una obra contemporánea, más ensayística o periodística que literaria.

DDL: Bueno, supongo que estarás ya muy ducha en lo que es el oficio de traductor literario en este año que lleva ya de experiencia. ¿También te has atrevido a formar parte de algún jurado de algún certamen de traducción literaria?

Neila GARCIA SALGADO Las cosas llegan, pero hay que echarles mucha paciencia
CLINA

vol. 7-1, June 2021, 77-84

elSSN: 2444-1961

Ediciones Universidad de Salamanca - CC BY-NC-ND 
NGS: No, hasta ahora nunca me lo habían propuesto. Experiencia realmente no tengo mucha. Me gradué hace cinco años de la Facultad. Encontraste un alma es mi segundo libro traducido. Hasta ahora traduje tres, además de algunos poemas que se fueron publicando en revistas. No tengo, ni por asomo, tanta experiencia como algunos de vuestros profesores o como algunos traductores que hayáis conocido. Y, perdóname, habías hecho otra pregunta, pero la olvidé.

DDL: Sí. ¿También tienes experiencia traduciendo obras literarias, por ejemplo, del inglés al español, de otros autores, de otras lenguas?

NGS: Pues en realidad, yo traduzco, como decíais en la presentación, del inglés y del alemán. Y del inglés traduzco mucho, pero sobre todo para organismos internacionales. Del alemán traduje un poquito al empezar a trabajar, pero por ahora no me ofrecieron ninguna obra literaria, ni del inglés ni del alemán, aunque me encantaría. Sobre los jurados, se me ofreció ahora el ser miembro del jurado de un premio de traducción de las Naciones Unidas y también, según tengo entendido, quienes reciben el Premio Nacional de Traducción forman parte del jurado en los dos años siguientes a aquel en que recibieron el premio.

DDL: Hablando de las Naciones Unidas, nos consta que trabajas como traductora para para la Oficina de las Naciones Unidas en Viena y que es allí donde resides. Entonces, nos gustaría saber si podrías contarnos un poco tu experiencia en ese empleo. ¿Cuál es tu día a día? ¿Cuáles son los grandes desafíos a los que te enfrentas?

NGS: Mi día a día varía, porque a veces trabajo para ellos in situ, en la oficina, con contratos de temporera, pero la mayor parte del tiempo lo hago como traductora externa. Es decir, como como traductora autónoma. El trabajo varía mucho dependiendo de si estoy en la Oficina de las Naciones Unidas o trabajando para ellos "desde casa». Por ejemplo, al estar en la oficina, hay muchos más documentos de conferencias, se hace generalmente trabajo más breve pero más urgente, mientras que el trabajo que se envía a los externos suele tener plazos más amplios. Hay excepciones, pero suelen ser textos más largos y con un plazo más amplio. La temática es muy variada en ambos casos. Depende de cuál de los organismos con sede en Viena tenga en ese momento, por ejemplo, una conferencia o más documentos para traducir. Varía mucho.

DDL: También, para todos aquellos estudiantes de la Facultad que nos puedan estar escuchando y que estén interesados en trabajar en algún tipo de institución europea dentro de unos años, nos gustaría saber cómo accediste a ese puesto de trabajo. ¿Fue mediante oposiciones? ¿Algún otro tipo de examen oficial?

NGS: Fue porque en 2014 - un año después de que me graduara - la Facultad convocó una pasantía remunerada en Viena. Fue un acuerdo entre la Facultad y la sección

Neila Garcia SALGADO Las cosas llegan, pero hay que echarles mucha paciencia
CLINA

vol. 7-1, June 2021, 77-84

elSSN: 2444-1961

Ediciones Universidad de Salamanca - CC BY-NC-ND 
de traducción al español en Viena, con mucho apoyo por parte del actual jefe de sección, Nero Capote. Yo envié mi solicitud y nos eligieron a mí y a mi compañera Marta Lucero, que estudió el máster en la Facultad. Nos vinimos las dos, en principio, dos meses cada una. Eso fue en otoño de 2014. Luego, nos fueron ofreciendo contratos: primero presenciales, pero por contrata, luego traducciones como traductoras externas y, por último, temporerías. No podemos trabajar en la Oficina con un puesto permanente porque ninguna de las aprobó el examen de oposición, por lo que solo podemos trabajar para las Oficinas de las Naciones Unidas con contratos temporales.

DDL: Hace unos días ya, el 2 de noviembre, llegamos un poco tarde para sugerir a algunos de nuestros oyentes que apliquen al programa Erasmus, pero igualmente nos gustaría preguntarte, porque sabemos que estuviste, como has dicho, de Erasmus en Gotemburgo y en Heidelberg y que son, al final, experiencias que han marcado tu vida y tu carrera profesional más tarde. Nos gustaría saber cuál es tu opinión sobre esta experiencia Erasmus, qué cosas ha aportado a nivel profesional, a nivel personal o incluso alguna experiencia especialmente curiosa o enriquecedora que te haya marcado durante ese tiempo.

NGS: Sí, la experiencia fue 100 \% positiva y, además, me alegra que menciones todos esos aspectos, no solo el académico, sino también el personal. Y por muchas razones. Aprendí sueco porque me fui a Gotemburgo. No digo que no lo hubiera podido aprender de otra forma, pero me facilitó mucho las cosas. Por otra parte, mi estancia en Alemania, además de ayudarme a mejorar mi alemán, me permitió seguir estudiando sueco, porque en las universidades alemanas la Escandinavística está bastante extendida. Luego, desde el punto de vista personal, en Gotemburgo hice muy buenas migas con una compañera de Salamanca que también había solicitado ir allí, a la que apenas conocía, y ahora somos muy buenas amigas. En Heidelberg hice unos amigos estupendos, un grupo de 7, y van a cumplirse casi 8 años desde que nos conocimos y nos vemos más de una vez al año. Tenemos una relación muy estrecha, son de mis mejores amigos.

DDL: Qué experiencia más bonita, realmente. Personalmente, yo quería hacerte una pregunta. Como estudiante de lenguas nórdicas, ¿piensas que hace falta una carrera, al igual que existe en Alemania o incluso en Inglaterra, de estudios escandinavos para poder continuar estudiando sueco, noruego, danés, etc.? Porque, en mi caso, que estuve estudiando una lengua nórdica, veo que al volver a España me encuentro que hay una falta de docencia de este tipo de asignaturas.

NGS: ¿Tú cuál estudias?

DDL: Estuve estudiando en Islandia y empecé a estudiar islandés, pero ahora tengo ese problema, de poder seguir.

Neila Garcia SALGADO Las cosas llegan, pero hay que echarles mucha paciencia
CLINA

vol. 7-1, June 2021, 77-84

elSSN: 2444-1961

Ediciones Universidad de Salamanca - CC BY-NC-ND 
NGS: Creo que hay necesidad, sí. En las Escuelas Oficiales de Idiomas, al menos de las ciudades más grandes, se están impartiendo, cada vez más, clases de lenguas nórdicas. Eso no ocurría, sin embargo, ni en la ciudad donde crecí ni tampoco en Salamanca. Yo soy de Ourense y por entonces se ofrecían muy poquitos idiomas en la escuela oficial de idiomas, y tampoco en Salamanca - que yo recuerde-había la opción de estudiar sueco, al menos cuando yo estaba ahí. El sueco que aprendí, para empezar, tuve que aprenderlo fuera y, en segundo lugar, es un sueco orientado a defenderse en el idioma, poder leer un poco en el idioma, pero sin un enfoque filológico. Si uno quiere traducir obras no contemporáneas o que pertenezcan a una minoría que difiera de los usos más estándares del idioma, que es lo que me pasó a mí, por ejemplo, con la obra de Edith Södergran, sí que necesita tener acceso a unos estudios reglados y con un enfoque filológico. No quisiera desalentar a nadie, pero estoy de acuerdo contigo en que si hubiera en España estudios de Escandinavística sería todo mucho más fácil, y redundaría en beneficio de todos.

DDL: Totalmente de acuerdo, desde luego. Yo quería hacerte una pregunta, en relación con algo que acabas de decir, que es tu lugar de origen. Tú naciste en Ourense, en Galicia, y aunque no lo hayamos mencionado tan frecuentemente como otras cosas en esta entrevista tú también traduces al gallego.

NGS: Sí.

DDL: Queríamos preguntarte cómo está el mercado de una lengua minoritaria como el gallego, pero minoritaria en el sentido de la cantidad de hablantes y de los problemas que tiene a la hora de hacerse un hueco, junto con las otras las grandes lenguas como puede ser el castellano.

NGS: Con tu pregunta te refieres en concreto a la traducción, ¿no?

DDL: Sí, a la traducción hacia el gallego.

NGS: Realmente no lo sé bien porque, como os decía, yo estudié en Salamanca, y, luego, lo que se me ofreció para traducir desde el gallego o hacia el gallego siempre fue documentación corporativa, nunca nada literario. Lo poco que os puedo contar parte de una conversación reciente que mantuve con un periodista que, además, es autor en lengua gallega y traductor. Lo que me decía es que, desde los años de la crisis -2008, 2009- , el volumen de traducciones al gallego se redujo muchísimo. Eso es lo que sé. Mi sensación desde fuera, porque no tengo manera de acceder a las librerías en Galicia más que cuando estoy de visita, es que, por ejemplo, se traduce mucho más hacia el catalán. No lo sé.

DDL: Sí, que quizás falta un impulso por parte de la gente de las editoriales o instituciones parecidas para potenciar la cultura.

Neila GarCia SALGADO Las cosas llegan, pero hay que echarles mucha paciencia
CLINA

vol. 7-1, June 2021, 77-84

elSSN: 2444-1961

Ediciones Universidad de Salamanca - CC BY-NC-ND 
NGS: Tal vez falte también apoyo por parte de determinadas instituciones. La verdad es que no lo sé.

E: Bueno, nosotros somos conscientes de que muchos de nuestros oyentes son estudiantes que están iniciando la carrera o que están terminando o que le gustaría estudiar Traducción e Interpretación. Me gustaría pedirte una reflexión acerca de tus años de carrera, si pudieras recomendar algo sobre la formación y sobre tus primeros pasos de egresada. ¿Qué es lo que te hubiese gustado que te hubiesen dicho cuando estabas en las aulas acerca del mundo laboral?

NGS: Yo creo que los profesores siempre fueron muy sinceros y no tengo la sensación, ahora que pasó el tiempo, de «ojalá me hubieran dicho esto». Creo que siempre nos animaron, al mismo tiempo que eran realistas y nos decían cómo era la situación, qué cabía esperar, qué nos íbamos a encontrar... Y acertaron bastante. Si echo la vista atrás, lo único que me gustaría haber sido es mucho más paciente, porque cuando terminé la carrera tenía la sensación de que algo, lo que fuera, iba a llegar, pero iba a llegar inmediatamente. Uno se busca la vida, solicita un trabajo, unas prácticas, una beca, todo. Muchas veces todo eso tarda en llegar. Es decir, uno tiene la sensación de estar invirtiendo muchísimo tiempo y energía en algo que no está llegando. Al final, si pienso en mis compañeros de promoción y yo, que nos graduamos hace cinco años, todos - todos o casi todos - hemos encontrado ya un sitio, permanente o no, en el que empezar a desarrollarnos profesionalmente. Las cosas llegan, pero hay que echarles mucha paciencia.

DDL: Desde luego, para para cualquiera que nos haya estado escuchando, tu trayectoria le va a servir de ejemplo porque es una inspiración para nosotros que alguno de los antiguos alumnos llegue a conseguir galardones tan importantes como estos, y que nos cuenten su experiencia y su trayectoria como ha llegado hasta aquí. Bueno, Neila, se nos va a terminando el tiempo de la entrevista. Queremos agradecerte una vez más que nos hayas dado la oportunidad de hablar con nosotros.

NGS: Gracias a vosotros.

Entrevista: «Don de Lenguas»

Transcripción: Beatriz Guerrero García

Enlace: https://programadondelenguas.blogspot.com/2018/11/entrevista-neila-garcia-salgado.html

Duración: 25:45:00

Neila Garcia SALGADO

Las cosas llegan, pero hay que echarles

mucha paciencia
CLINA

vol. 7-1, June 2021, 77-84

elSSN: 2444-1961

Ediciones Universidad de Salamanca - CC BY-NC-ND 


\section{NOTA BIOGRÁFICA}

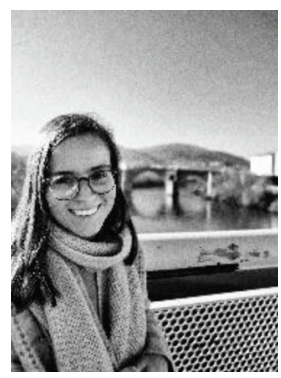

Neila García Salgado (Ourense, 1991) es traductora e intérprete. Sus principales lenguas de trabajo son el inglés, alemán y sueco, de las que traduce al español y al gallego. Graduada en Traducción e Interpretación por la Universidad de Salamanca, completó sus estudios en la Universidad de Gotemburgo (Suecia) y la Universidad de Heidelberg (Alemania). En la actualidad se dedica fundamentalmente a la traducción y reside en Viena, donde compagina encargos editoriales con otros como traductora externa y traductora temporal de la Oficina de las Naciones Unidas. Ha vertido más de una decena de títulos al español, de autores clásicos y contemporáneos, entre los que cabría destacar a Hjalmar Söderberg, Edith Södergran, Ken Kesey, Lars Gustafsson y Theodor Kallifatides. En 2018, el Ministerio de Cultura y Deporte le concedió el Premio Nacional a la Mejor Traducción por Encontraste un alma, la poesía completa de la poeta Edith Södergran.

Neila García Salgado: https://es.wikipedia.org/wiki/Neila_Garc\%C3\%ADa_Salgado

\section{TRADUCCIONES}

Edith Södergran. 2017. Encontraste un alma.

Hjalmar Söderberg. 2014. Lana juventud de Martin Birck.

Lars Gustafsson y Agneta Blomqvist. 2014. Imágenes de Suecia.

Neila GARCIA SALGADO Las cosas llegan, pero hay que echarles mucha paciencia 